\title{
La muerte del vicepresidente: epidemias y crisis en Buenos Aires (1867-1868)
}

\section{The Vice President's Death: epidemics and crises in Buenos Aires (1867-1868)}

\author{
Maximiliano Ricardo Fiquepron \\ Consejo Nacional de Investigaciones Científicas y Técnicas \\ Universidad Nacional de General Sarmiento \\ Instituto de Ciencias \\ (Argentina) \\ mfiquepr@ungs.edu.ar
}

\section{Resumen}

En el siguiente artículo analizaremos la dimensión ritual de los funerales y su vinculación con un evento muy presente durante todo el siglo XIX: la llegada y la diseminación de sucesivas epidemias de cólera. El argumento que sostenemos es que las mismas provocaron crisis sociales profundas, afectando todas las esferas de la vida social. Este tipo de episodios traumáticos, generó un proceso doble conectado a los ritos mortuorios. Por un lado, trastocaron los rituales más usuales, y por otro, esto ocasionó que la sociedad porteña desplegara otros suplementarios para que los difuntos tuvieran sus funerales. Para ello, en un primer apartado presentaremos las prácticas fúnebres tradicionales en Buenos Aires, así como las características disruptivas del cólera. Asimismo, veremos que la sociedad porteña tenía un repertorio amplio y dúctil de prácticas fúnebres, y si bien ante la epidemia no pudo desarrollar aquellas más habituales, surgieron otras para paliar el cambio en el escenario por la crisis desatada. Pero además de alta mortalidad, estas epidemias acentuaron crisis políticas y tensiones sociales, que se dirimieron tanto durante sus desarrollos como inmediatamente después. Para ello, en un segundo apartado, examinaremos la muerte del vicepresidente Marcos Paz, fallecido de cólera durante el verano de 1868. Postulamos que el Estado será un factor esencial en los homenajes a algunos muertos, sobre todo aquellos que le permitían reencauzar conflictos institucionales y/o políticos. De esta manera, nuestro argumento sostiene que los rituales fueron un elemento central para normalizar conflictos que excedían aquellos más evidentes.

Palabras Clave: Epidemias - Funerales - Estado - Buenos Aires - Siglo XIX 


\begin{abstract}
In this article we will discuss the ritual dimension of funerals and its connection with an important event throughout the XIX century: the arrival and spread of cholera epidemics. The argument that we make is that epidemics caused deep social crises, affecting all spheres of social life. These traumatic events generated a double process regarding mortuary rites. On one hand, the most usual rituals were interrupted. On the other, Buenos Aires society developed supplementary rituals so that the deceased could have their funerals. The first section of this paper will present common funeral practices in Buenos Aires and the disruptive characteristics of cholera. We will see that Buenos Aires's society had an wide and ductile repertoire of funeral practices, and though during the epidemics it would not be possible to let the most common ones happen, some others emerged to mitigate the change in the scenario unleashed by the crisis. The other process was that, in addition to demographic crises, epidemics accentuated political crises and social tensions, which were settled both during and immediately after the epidemics. To this end, a second section will examine the death of cholera of Vice President Marcos Paz during the summer of 1868. We postulate that the State was an essential factor in the tributes to some dead, especially those that allowed redirecting institutional and / or politic conflicts. Thus, our argument is that the rituals were a key element to normalize conflicts that exceeded the demographic crisis alone.
\end{abstract}

Key Words: Epidemics - Burials - Estate - Buenos Aires - XIX Century

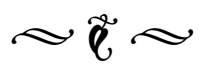

\section{Introducción}

De acuerdo a distintas convenciones lingüísticas y sociales, una epidemia se define como la propagación de una enfermedad durante algún tiempo por un país o región, acometiendo simultáneamente a gran número de personas. Sin embargo, también es claro que una epidemia es mucho más que la expansión espacio-temporal de un virus o bacteria. Por la llegada de la peste bubónica, el cólera, la fiebre amarilla y la viruela, se producían crisis de mortalidad y la población perdía su relación con elementos centrales de la vida cotidiana (como trabajar, alimentarse, educarse) y aquellos que podían hacerlo, huían rápidamente de sus hogares. Los cadáveres quedaban abandonados, y las autoridades comenzaban la ingrata y terrible tarea de inhumarlos, así como también la de asistir a los enfermos y menesterosos. A causa de la huida de la población de la ciudad, se producían también robos a las propiedades abandonadas, pululaban charlatanes y falsos médicos vendiendo "curas infalibles", y muchas personas quedaban sin protección ni vivienda por los desalojos forzosos que las autoridades realizaban. ${ }^{1}$ Es por ello que,

1. CARBONETTI, Adrián, RODRIGUEZ, María Laura, RIMONDA, Noelia, MARTINA, Camila, "Las epidemias de cólera en Córdoba a través del periodismo: la oferta de productos preservativos y curativos durante la epidemia de 1867-1868", en Historia, Ciencia, Saúde Manguinhos, Rio de Janeiro, 2007, V. XIV, No 2, pp. 405419; CARBONETTI, Adrián, "Medicalización y cólera en Córdoba a fines del siglo XIX. Las epidemias de 1867-68 y 1886-87", en Anuario de Historia Regional y de las Fronteras, Bucaramanga, 2016, V. XXI, No 2, pp. 285309; ÁLVAREZ, Adriana, "La aparición del cólera en 
tanto como la expansión espacial y temporal de un microorganismo, es central comprender que las epidemias eran crisis sociales, donde jugaban un papel fundamental el miedo y la muerte súbita y masiva. Ellas provocaban una respuesta inmediata y generalizada de todos los sectores de la población: acciones del Estado, reacciones desde la religión, manifestaciones de solidaridad comunitaria, y también robos, saqueos, y violencia hacia los que se señalaba como culpables de expandir la enfermedad. En síntesis, la alta mortalidad, la rápida propagación, los síntomas severos, y sobre todo el colapso en las maneras de reproducir la vida cotidiana daban forma al carácter dramático y revulsivo esencial de estas epidemias. La interpretación de este particular estado como una crisis, implica caracterizar y comprender las modalidades específicas de experimentación e interpretación de ese estado crítico por parte de los sujetos sociales, que eran tanto respuestas frente a condicionantes externos como vehículos de constitución de estos estados críticos como eventos. ${ }^{2}$

Para adentrarnos en estos temas, en este artículo proponemos analizar la dimensión ritual de los funerales y su vínculo con la llegada y diseminación de epidemias, específicamente el cólera, que atravesó los años 1867 y 1868 . Toda una tradición en las ciencias sociales ha entendido por ritual a una acción gobernada por reglas, reiterada en ocasiones especiales, conformando secuencias de actos simbólicos estandarizados. Una idea

Buenos Aires (Argentina), 1865-1996", en HiSTOReLo. Revista de Historia Regional y Local, Medellín, 2012, V. IV, No 8, pp. 174-207.

2. VISACOVSKY, Sergio (compilador) Estados Criticos: la experiencia social de la calamidad, Al Margen, La Plata, 2011, p. 19. muy presente en el estudio de estas prácticas, es que ellos permiten facilitar el tránsito de una posición socialmente definida a otra. De esta manera, son necesarios para exorcizar lo disruptivo del pasaje, el caos que puede afectar a una sociedad en un momento dado. Junto con esta idea también se une otra, que se asocia al significado expresado en los rituales y el contexto cultural más amplio en el cual son realizados. Si bien es parte constitutiva de su lógica que se respete la secuencia de reglas y gestos, también pueden acontecer cambios en su forma y efectos, ${ }^{3}$ permitiendo pensarlos como prácticas dinámicas (y no como escenarios estáticos) que muestran códigos culturales antagónicos y heterogéneos, con intereses sociales y políticos diferentes. ${ }^{4}$ De esta manera, nos preguntamos: ¿Cómo respondió la sociedad porteña al fenómeno producido por la alta mortalidad que generó una de las enfermedades consideradas letales para la época como lo fue el cólera? ¿Con qué elementos contó para sobrellevar el desarrollo de episodios traumáticos y conflictivos,

3. PARKIN, David, "Ritual”, en Baltes, Paul and Smelser, Neil, International Encyclopedia of the Social E Behavioral Sciences, Elsevier, Amsterdam, 2001, pp. 13368-13371. Disponible en: <http://www.sciencedirect. com/science/referenceworks/9780080430768>; PAYNE, Richard, "Locating Buddhism, Locating Psychology", en YOUNG-EISENDRATH, Polly y MURAMOTO, Shoji (editores) Awakening and Insight: Zen Buddhism and Psychotherapy, Brunner/Routledge, Londres y New York, 2002, p.172.

4. GAYOL, Sandra, "Los despojos sagrados: funerales de estado, muerte y política en la Argentina del Centenario", en TATO, María Inés y CASTRO, Martín (compiladores) Del Centenario al peronismo. Dimensiones de la vida politica argentina, Imago Mundi, Buenos Aires, 2010; GAYOL, Sandra y KESSLER, Gabriel (compiladores) Muerte, politica y sociedad en la Argentin, Edhasa, Buenos Aires, 2015; SUZUKI, Hiraku, The price of Death: The Funeral Industry in Contemporary Japan, Stanford University Press, Stanford, 2000. 
no sólo a nivel demográfico sino también institucional y político, en especial cuando incidieron en el complejo escenario de crisis política y social de las décadas de 1850 y 1860 ?

Con estas premisas, nuestro argumento es que las epidemias generaron un proceso doble conectado a los ritos mortuorios. Por un lado trastocaron los rituales más usuales, ante lo cual la sociedad porteña desplegó otros suplementarios no sólo para que los difuntos tuvieran sus funerales, sino sobre todo, para poder atravesar una crisis profunda y corrosiva. Para ello, en un primer apartado, presentaremos las prácticas fúnebres habituales en Buenos Aires, así como las características disruptivas del cólera. Veremos que la sociedad porteña tenía un repertorio amplio y dúctil de prácticas fúnebres, y si bien ante la epidemia no pudo desarrollar aquellas más tradicionales, surgieron otras para paliar el cambio en el escenario por la crisis desatada. Por otro lado, además de la alta mortalidad ocasionada, se acentuaron tensiones sociales $y$ políticas, que se dirimieron tanto durante la epidemia como inmediatamente después. Para ello, en un segundo apartado, examinaremos la muerte del vicepresidente Marcos Paz, a causa del cólera, durante el verano de 1868. Postulamos que el Estado fue un factor esencial en su homenaje, buscando con ello reencauzar una crisis institucional y también política. De esta manera, nuestro argumento sostiene que los rituales podían ser utilizados para normalizar conflictos que excedían la crisis demográfica.

\section{Rituales fúnebres durante el cólera en Buenos Aires}

La ciudad de Buenos Aires tenía una larga convivencia con epidemias y enfermedades: viruela, sarampión, escarlatina y fiebre tifoidea conformaban un aspecto más de la vida cotidiana. ${ }^{5}$ Sin embargo, este escenario sería modificado profundamente con la llegada, hacia la segunda mitad del siglo XIX, de una de las enfermedades más agresivas del siglo: el cólera. Entre 1867 y 1868 se estima que la provincia de Buenos Aires tuvo alrededor de 15.000 víctimas, de una población total de 495.107 habitantes. ${ }^{6}$ Este mal se extendió no sólo en la ciudad y sus pueblos vecinos, sino en toda la campaña bonaerense y provincias argentinas. Produjo altos índices de mortalidad y tuvo repercusiones sociales e incluso políticas, debido a una serie de particularidades que producían aversión y pánico en todos los lugares a los que arribaba.

Al ser una enfermedad desconocida para la población, despertaba toda una serie de rumores, temores e inquietudes, que se sumaban a la brutal deshumanización

5.En la mortalidad general, la causada por estas enfermedades infectocontagiosas tuvieron una participación importante entre 1869 y 1889: en promedio el $14.4 \%$ y en algunos años superaron el $20 \%$. Entre las enfermedades se ubicaban, según un orden de importancia de acuerdo a la población infectada, la tuberculosis en primer lugar, seguida por la viruela. La difteria y la fiebre tifoidea formaban parte de los miedos más extendidos, pero porcentualmente eran menores. ÁLVAREZ, Adriana, MOLINARI, Irene, REYNOSO, Daniel (editores) Historias de enfermedades, salud $y$ medicina en la Argentina de los siglos XIX-XX, Universidad Nacional de Mar del Plata, Mar del Plata, 2004, p. 24.

6. PENNA, José, El cólera en la Argentina, Editorial Jacobo Peuser, Buenos Aires, 1897; PRIETO, Agustina, [et. al], Ciudad de Rosario, Editorial Municipal de Rosario, Rosario, 2010. 
que sufrían los atacados, ya que, en su momento más álgido, se producía una rápida deshidratación a causa de diarrea y vómitos agudos. Otros síntomas que acompañan este cuadro, eran calambres muy intensos en la región abdominal y en las extremidades, presión arterial baja y pérdida de temperatura corporal. La manifestación física de este colapso se expresaba a través de la coloración cianótica de la piel y el hundimiento en las cuencas oculares así como la postración y decaimiento severo del cuerpo producto de la deshidratación, que le otorgaban al enfermo un aspecto marcadamente lívido, como si ya estuviera muerto. Una de las características más atemorizantes era la velocidad con que podía producir la muerte, a veces, en el transcurso de algunas horas. Esta particular sintomatología ha sido considerada un factor central para comprender las respuestas sociales -sobre todo el pánico- que se generaron a su alrededor. $^{7}$

De manera que la llegada del cólera impuso una dura prueba a la sociedad porteña, dado que más allá de los debates de especialistas, la creencia popular era que los enfermos contagiaban. El método preventivo consistía en abandonar el foco de infección, es decir, alejarse de toda persona enferma o de cadáveres producidos por la epidemia. Así, cientos de familias emigraron masivamente hacia las afueras de la ciudad de Buenos

7. EVANS, Richard, Death in Hamburg: Society and Politics in the Cholera Years, Penguin Books, New York, 1987; ROSENBERG, Charles, The Cholera Years: The United States in 1832, 1849 and 1866, The University of Chicago Press, Chicago, 1962; RANGER, Terrence y SLACK, Paul (editores) Epidemics and Ideas: essays on the historical Perception of Pestilence, Cambridge University Press, Cambridge, 1992; SNOWDEN, Frank, Naples in the Time of Cholera, 1884-191, Cambridge University Press, Cambridge, 1995.
Aires, asentándose no sólo en los pueblos más cercanos como Flores, Belgrano, Morón y el por entonces llamado Barracas al Sud (el actual partido de Avellaneda), sino que se adentraron en localidades de hasta 100 kilómetros de la ciudad, como Mercedes y Lobos. ${ }^{8}$ Este éxodo adquirió características dramáticas cuando las familias abandonaban a sus enfermos $y$ difuntos, lo cual fue sancionado desde la prensa y otras memorias posteriores, que recordaron esos días como una ruptura de la moral y el lazo social. De esta manera, la crisis no sólo se expresó en la capacidad de sobrevivir sino además en el impacto producido por la disrupción de redes de sociabilidad y ayuda mutua, marcos morales dictados por la religión, y la propia experiencia de un mundo conocido que se desintegraba.

Durante las epidemias de cólera de 18671868, el entramado ritual que acompañaba la muerte de un sujeto, sufrió notables modificaciones, afectando todas las etapas de lo que se conocía como el "buen morir". En primer lugar, la agonía de la persona se esperaba que aconteciese en el domicilio, junto a su familia. Una vez fallecida, parientes y allegados buscaban desplegar una sucesión de ceremonias religiosas ligadas a homenajear al difunto (sobre todo eran ineludibles los

8. No hay cifras definitivas sobre la cantidad de emigrados a los pueblos vecinos durante las epidemias de cólera en Buenos Aires. Sí las hay para la fiebre amarilla de 1871 (otra de las grandes epidemias que tuvo la ciudad). En esta se estima que hasta la primera semana de marzo -todavía no el mayor pico de mortalidadhabían huido de la ciudad 53.425 personas. La población total de la ciudad era de 187.126 habitantes. Hasta fines de marzo continuó esta tendencia, lo que supone una cifra muy elevada de emigrados. SCENNA, Miguel Ángel, Cuando murió Buenos Aires. 1871, Cántaro, Buenos Aires, 1974, p. 223. 
velorios y las misas). Por último, restaba el entierro en el cementerio, rodeado no sólo por familiares, sino por una comitiva que reflejara la filiación del difunto con la comunidad de la que formaba parte. Varios autores señalan que existía una integración entre el teatro de la vida y el de la muerte: los velorios realizados en las casas, ${ }^{9}$ la cercanía entre los cementerios y las iglesias; los vivos enterraban a sus muertos en templos donde habían sido bautizados, confesados, casados y habían asistido a misa. La vida religiosa, tenía un fuerte componente parroquial. ${ }^{10}$

9.Joao Reis menciona que en el momento de la agonía del enfermo se cubrían con cortinas oscuras todas las ventanas para impedir entrar al diablo, mientras que una vez que aquel hubiera fallecido se descubrían las mismas para que el alma viajara libre hacia el cielo. REIS, Joao, A morte e uma festa. Ritos funebres e revolta popular no Brasil do século XIX, Companhia das letras, Sao Paulo, 1991, p. 101. Sin embargo, Lilian Diodati y Nora Liñan encuentran que para Buenos Aires, la iluminación domina la sala del moribundo. Se esperaba que la sala donde se encontraba el enfermo "estuviera alumbrada lo mejor posible" así como abiertas las ventanas; preferentemente en una habitación que diera a la calle. DIODATI, Lilian y LIÑAN, Nora, "Gestualidad y sentido de la muerte en Buenos Aires durante la primera mitad del siglo XIX", en GODOY, Cristina y HOURCADE, Eduardo (compiladores) La muerte en la cultura. Ensayos históricos, Universidad Nacional de Rosario Editora, Rosario, 1993, p.153.

10. REIS, Joao, "O cotidiano da morte no Brasil Oitocentista” en NOVAIS, Fernando (director) Historia da vida privada no Brasil. T. II, Imperio: a corte e a modernidade nacional, Compania das Letras, Sao Paulo, 1997. En nuestro estudio hemos decidido enfocarnos específicamente, en el rito católico, ya que la población pertenecía mayoritariamente a ese culto. Otras religiones con influencia importante (como protestantes, judíos y las comunidades afroporteñas, por ejemplo), tenían otros ritos. A modo de ejemplo, ver: AA.VV. Patrimonio cultural en cementerios y rituales de la muerte, Gobierno de la Ciudad de Buenos Aires, Buenos Aires, 2005. (dos volúmenes).

6
Todos y cada uno de estos elementos se dislocaban durante la crisis social que producía el cólera. Comencemos con el primer paso: la agonía y el fallecimiento del sujeto. Durante las epidemias, en vez de congregar a su alrededor deudos que fueran testigos de sus últimas horas, el enfermo era evitado, debido a que, en general, la población creía que los afectados por el mal y los cadáveres contagiaban. Si bien muchos individuos fallecieron solos, sin ayuda ni soporte, desde distintas instituciones de caridad y entidades del Estado (municipal y provincial) se llevaron adelante acciones destinadas a paliar esta crisis de asistencia. Entre las medidas más habituales, el traslado al Lazareto de toda persona diagnosticada de cólera fue una de las primeras en implementarse. ${ }^{11}$ Paradójicamente, esto no era visto por la población como un signo esperanzador, sino más bien como lo opuesto. Tanto el lazareto como el hospital eran considerados indecorosos, destinados a mendigos y personas que no tenían vínculos suficientemente fuertes en la comunidad. Acentuando las diferencias con las medidas habituales, se sumaba la presencia del médico en los momentos finales del enfermo. Para entonces las prácticas recomendadas por los facultativos no eran aceptadas por todo el conjunto social y muchos se resistían a ellas. Así, no sólo la peste generaba la repulsión

11. Para 1867 se reportan las primeras medidas en el brote que se desarrolló entre marzo y abril. Posteriormente, para octubre ya se estipula tener preparado los lazaretos ante rumores de casos en el ejército del Paraguay. Actas del Concejo Municipal de la ciudad de Buenos Aires, correspondiente al año 1867, Tall Gráficos “Optimus”, Buenos Aires, 1911. Sesión del 7 de junio de 1867, p. 111. Para 1871, en las sesiones aparecen hacia el 14 de febrero alusiones a enviar los enfermos al lazareto. Actas del Concejo Municipal..., Op. Cit., año 1871, p. 47. 
del agonizante, sino que su envío al Lazareto u hospital modificaba drásticamente el escenario donde transcurrían sus últimos momentos. $^{12}$

La segunda instancia del proceso ritual también sufría notables cambios. En períodos no epidémicos, era esencial el lugar ocupado por el velorio, ya que era tanto un mecanismo que permitiría tener certezas de la defunción -despertarse enterrado vivo era un temor de la época- ${ }^{13}$ como una prescripción de la religión católica. Además, al igual que otras ceremonias, la concurrencia al evento era esencial para todos los sectores sociales. La instancia de sociabilidad de los velorios contemplaba el consumo de bebidas alcohólicas así como también de infusiones como el té y el mate, además de actividades recreativas como el juego de cartas, el baile, que en ocasiones producía altercados violentos entre los deudos. La dimensión religiosa también estaba presente: se rogaba por el alma del difunto a través del rezo colectivo del Rosario, sin perder la tónica de reunión y convite. Como señala María Elena Barral, este comensalismo colectivo y festivo excedía las celebraciones de la muerte, y se presentaba como una de las maneras más habituales de confraternización y de integración simbólica de la comunidad, o de parte de ella. ${ }^{14}$

12. ALVAREZ, Adriana, "El rol de los Lazaretos en el control de el cólera y la fiebre amarilla. Buenos Aires 1870-1915”, en História Revista, Goiás, 2004, V. IX, No 2, pp. 287-317.

13. ARIES, Philippe, El hombre ante la muerte. Taurus, Madrid, 1983, p. 301.

14. BARRAL, María Elena, De sotanas por la pampa. Religión y sociedad en el Buenos Aires rural tardocolonial, Prometeo libros, Buenos Aires, 2007, p.194.
Durante los períodos epidémicos, podemos observar cómo esta segunda instancia del proceso ritual sufría notables transformaciones. Al igual que lo acontecido con los enfermos en su lecho de muerte, los cadáveres tenían un destino desprovisto de las prácticas fúnebres más difundidas, sobre todo cuando las autoridades decidían prohibir los velorios, lo que acrecentaba el temor de enterrar viva a la persona. Las medidas tomadas fueron en torno a la inhumación sumaria, el uso de cal, y el sellamiento de las bóvedas. ${ }^{15}$ Sin embargo, más allá de las prohibiciones que desde la Municipalidad de la ciudad se intentaron implementar, las dimensiones extraordinarias de la mortalidad también imposibilitaron a la mayoría de la población otorgar los funerales habituales. Con el incremento de fallecimientos, a principios de diciembre, la policía y las comisiones de vecinos parroquiales quedaron designadas en la gestión y entierro de los cuerpos, quitándole a la familia su rol habitual.

E1 tercer momento, era el camino al cementerio y la inhumación. El recorrido del cadáver tenía un sentido de congregación, de demostración de aquellos deudos que se acercaban a acompañar al difunto hasta su última morada. Una vez más lo que ocurrió fue la inversión de los patrones comunes. Si antes los "convoy fúnebres" se componían de al menos diez carruajes, durante el cólera no se daba abasto para transportar los restos, y se trasladaba a la mayor cantidad posible en un mismo vehículo, en general en carros que usualmente se destinaban para recolectar los residuos de la ciudad. Así, policías, miembros de las comisiones

15. Actas del Concejo Municipal..., Op. Cit, p. 85. Sesión 3 abril de 1867. 
de higiene parroquiales, peones y carreros, gestionaron el acompañamiento y entierro de los muertos, se volvieron el "cortejo fúnebre" que las epidemias generaron. En esta tercera etapa, tan importante como el abastecimiento de medios de transporte al cementerio, fue la necesidad de una procesión. $\mathrm{Y}$ este era uno de los puntos más traumáticos que provocaban estas epidemias. La crisis general desatada imposibilitó la dimensión ritual de transportar el cadáver, convirtiendo este último tramo en un acto administrativo. $\mathrm{Su}$ recorrido final, no sólo era en un carro que no tenía como función original transportar muertos, sino que además lo hacía junto con otros cajones anónimos. Al llegar al cementerio, la inhumación se realizaba en fosas comunes, un destino que usualmente recibían aquellos sin ningún vínculo familiar que los contuviera, produciendo un golpe muy duro a las jerarquías simbólicas, dado que este trato era sinónimo de no pertenencia, lo contrario a ser un vecino reconocido e integrado en la comunidad. La presencia de una lógica y dinámica distinta a las prácticas comunitarias, acentuó las profundas grietas en la trama social que las epidemias -por su propia dinámica- generaban, volviendo anónimos a los fallecidos, e imposibilitando otorgar un escenario adecuado a los difuntos.

Sin embargo, si bien los rituales fúnebres habituales no pudieron ser llevados adelante en su total dimensión, los deudos y familiares de los fallecidos desplegaron un repertorio flexibledeprácticas quecombinaban elementos usuales con otros más improvisados. Una de ellas consistía en intentar que el cadáver recibiera un mejor ataúd y transporte que el entregado por las autoridades de la ciudad. La intención de evitar un trato indecente aparece reflejada en los partes diarios de los comisarios de policía, quienes informaban meticulosamente el destino de cada cadáver. En la mayoría de los casos el cuerpo recibía "cajón y carro" otorgado por la policía o las comisiones. Pero en otros, se facilitaba un cajón a los familiares para que ellos mismos lo trasladasen, o se permitía que los allegados utilicen el transporte oficial que se proveía, pero en un féretro de mejor calidad adquirido por ellos. También -en menor medida- las autoridades podían limitarse solamente a expedir el certificado de sepultura, en este caso los deudos se encargaban de conseguir un ataúd y coche. En cualquiera de estas variantes, era central el lugar que conservaba la familia, buscando garantizar al difunto los mínimos cuidados.

De ser posible, una vez vuelta la normalidad, se intentaba conocer dónde había sido inhumado el cuerpo para realizarle las exequias que no se habían podido concretar. Los obituarios publicados en la prensa a los pocos meses de finalizadas las epidemias muestran el esfuerzo de las familias por otorgar funerales a sus deudos, así como también el pedido de novenarios durante los períodos más intensos, cuando no existían condiciones materiales de efectuarlos. ${ }^{16}$ También, desde las autoridades, se realizaron ceremonias religiosas, con la intención de homenajear a los caídos y celebrar el fin de la epidemia. Más allá de las organizadas por los particulares, se llevaron adelante un $T e$

16. El novenario es una devoción pública o privada que se realiza durante nueve días cuya intención es obtener gracias especiales ante algún evento como una buena cosecha, o para pedir que se terminen pestes, sequías y plagas. Siendo una práctica de las más antiguas, su elección como ceremonia alternativa es porque no necesita excluyentemente la asistencia al templo, y de allí el pedido por los familiares de los difuntos para homenajearlo desde sus hogares. 
Deum en la Catedral de la Ciudad, y desde distintas asociaciones civiles se fomentó el reconocimiento de aquellos que murieron ayudando a los enfermos. Los cronistas siempre hacen referencia a "una nutrida concurrencia" que se congregó para estos eventos. En una de sus cartas, Guillermo Rawson informaba al presidente Bartolomé Mitre que “...Ayer sepultamos el cadáver del Dr. Paz. A pesar del riguroso calor y de los pavores que causa la epidemia, hubo una concurrencia inmensa en el entierro, siendo universales y muy sentidas las muestras de condolencias que se notan en el pueblo por la pérdida de este digno magistrado y virtuoso ciudadano." De manera que el Estado nacional garantizó al Vicepresidente de la República fallecido en la epidemia de cólera, exequias acordes a su investidura y, como veremos, a las exigencias políticas del momento. Ni siquiera la muerte en situaciones extraordinarias borró las distinciones sociales y su capacidad, a través del rito y su significado simbólico, de marcar las diferencias de poder social y político. Sin embargo, es necesario destacar que los muertos que en el marco de la epidemia recibieron este tipo de reconocimiento, e incluso los ritos fúnebres, habituales fueron una excepción. ${ }^{17}$

17. He desarrollado en detalle este punto en FIQUEPRON, Maximiliano, Morir en las grandes pestes: Estado, sociedad y representaciones sobre la muerte durante las epidemias de cólera y fiebre amarilla en Buenos Aires. (1856-1886), Tesis de doctorado, Universidad de General Sarmiento, 2015. Asimismo, he explorado la capacidad de la epidemia para rendir honores fúnebres y "reconocer grandes hombres civiles" en: FIQUEPRON, Maximiliano, "Cadáveres, epidemias y funerales en Buenos Aires (1856-1886)", en GAYOL, Sandra y KESSLER, Gabriel (editores) Muerte..., Op. Cit., pp. 227-250.

\section{La muerte del Vicepresidente}

En la noche del 2 de enero de 1868, en medio del mayor pico de mortalidad (con un promedio de 80 muertos por día), Guillermo Rawson -para entonces Ministro del Interior- escribía al Presidente Bartolomé Mitre, quien se encontraba desempeñándose como Comandante General de los Ejércitos Aliados en guerra con Paraguay:

Mi querido presidente y amigo: Ayer le escribí avisándole la enfermedad del vicepresidente y el favorable camino que seguía. Pero desde esta madrugada se ha agravado de tal suerte, que apenas tengo esperanzas de salvarle la vida.

Llego en este momento (11 de la noche) de San José de Flores, donde él está. Los síntomas del cólera se han desarrollado en una forma de las más alarmantes, sigue la profunda postración y se le presenta un síntoma, la hemorragia del estómago, que he mirado siempre como fatal.

Casi a todas horas estoy a su lado, y continuaré así hasta que se decida la suerte de este amigo.

Entretanto, es preciso que usted se prepare a venirse inmediatamente, si por desgracia llegase a fallecer el Dr. Paz. No sé lo que haremos en ese caso para dar movimiento a la maquina mientras usted llega. Nos inspiraremos de las circunstancias provisoriamente.

Si esa funesta novedad ocurre, se lo avisaré a usted sin pérdida de un momento por un vapor expreso.

Su afmo. amigo - G. Rawson. ${ }^{18}$

18. Archivo Mitre (en adelante AM), Correspondencia 
Por la mañana, Rawson envió otra carta a Mitre desde el pueblo de San José de Flores, confirmándole que "sigue gravísimo el estado del Dr. Paz. Creo que no pasará el día de hoy. He mandado preparar un expreso para que lleve a usted la triste noticia, en caso de verificarse". ${ }^{19}$ Lejanas quedaban las expectativas de este médico y Ministro del Interior, que algunos días antes diagnosticaba una convalecencia leve ante lo que él entendía había sido "una colerina que amenazaba por momentos tomar formas y proporciones muy alarmantes". Al momento de su muerte, la ciudad semidesierta se cubrió de nuevas escenas y actores: médicos y visitadores domiciliarios, fogatas de alquitrán en las esquinas, casas cerradas, enfermos por las calles y carros fúnebres en dirección al recientemente creado Cementerio del Sur y también al Cementerio de la Recoleta.

De acuerdo con la prensa, su muerte aconteció a las 13 horas -algunos como $\mathrm{La}$ Tribuna afirmaban que fue a las 12 horas-. La conmoción principal fue política: no había en la Constitución Nacional un sucesor directo del Vice presidente en ejercicio si éste fallecía. Si bien el artículo 72 de la Constitución Nacional de 1853 aludía a un procedimiento de sucesión, que consistía en que el Congreso Nacional dictaminara un funcionario público provisorio en caso de renuncia o muerte del vicepresidente y el presidente "hasta que haya cesado la causa de la inhabilidad o un nuevo presidente sea electo", ${ }^{20}$ la muerte de

Rawson-Mitre., p. 55.

19. AM, correspondencia Rawson-Mitre. p. 56.

20. Este artículo pasará a ser el número 75 en el texto constitucional revisado por Buenos Aires en 1860. Posteriormente será el artículo 76 en la constitución de 1949, y el 88 de la reforma constitucional de 1994.
Marcos Paz ocurría mientras el Congreso Nacional estaba en receso. Esto significaba que la posibilidad de reunir a los diputados y senadores de las distintas provincias se volvía una tarea que podía requerir semanas, dado que muchos de ellos volvieron a sus provincias natales, lo que abría un frente de inestabilidad política muy agudo.

Los funcionarios y aliados políticos enviaron cartas a Mitre explicitando "una verdadera urgencia en que usted venga a ponerse al frente del Gobierno". ${ }^{21}$ Ante ello, los ministros del Poder Ejecutivo Nacional emitieron un decreto informando que se conformarían en un Consejo de Gobierno hasta la llegada del presidente. Luego de esta resolución, se reunieron con Adolfo Alsina, gobernador de la provincia de Buenos Aires, en una búsqueda evidente de consenso entre sectores enfrentados políticamente, dado que para entonces, estaba abierta la carrera a la sucesión presidencial de 1868, y Alsina especulaba con una candidatura a la presidencia.

Esta inusual situación política no pasó desapercibida para otras figuras nacionales. En la correspondencia que el General Urquiza mantenía con sus jefes políticos de Entre Ríos y con contactos en Buenos Aires, aparece claramente la especulación de tomar partido político de la crisis institucional por la que atravesaba el gobierno nacional a raíz del cólera. En una carta del 4 de enero, Carlos Olhsen $^{22}$ le informaba a Urquiza la terrible

BARRANCOS Y VEDIA, Fernando, Alternativas de la acefalia presidencial, Academia Nacional de Ciencias Morales y Políticas, Buenos Aries, 2004.

21. AM, Correspondencia Rawson a Mitre, 4 enero de 1868, p. 56; AM, Elizalde a Mitre , 2 enero de 1868. p. 213.

22. Carlos Olhsen era un comerciante de exportación, 
situación por la que estaba atravesando Buenos Aires, avisándole que “...un vapor debe ir hoy en busca de Mitre, y por cierto, creo verdaderamente que de necesidad tendrían todos que llamar a S.E [Urquiza] por el arreglo de la horrible situación del País. $\mathrm{Ni}$ otro que Ud., se cree, podrá arreglarlo". En otra misiva, enviada por el jefe político de Concepción del Uruguay el 6 de enero, resumía muy claramente el problema institucional y las especulaciones entrerrianas:

La muerte de Paz ha dejado en completa acefalia al gobierno hasta que venga a ocuparlo Mitre; y si el cólera nos hiciese el favor de llevarse a éste último, tendrían las provincias que asumir su soberanía. / Como quiera que sea, la muerte de Paz trae un conflicto porque produce una situación enteramente nueva. Por el pacto tratado le corresponde el mando en Jefe del Ejército aliado al jefe del país más inmediato al Teatro de la Guerra. ¿Cómo se hace para que Mitre esté en dos partes al unisonó? Partido medio a medio. ${ }^{23}$

De manera que el cólera se insertaba profundizando y reconfigurando tensiones políticas que presagiaban un retorno a los conflictos armados entre las provincias, dado que dos de las figuras nacionales más importantes (Urquiza y Alsina) se presentaban como candidatos con proyectos de Estado enfrentados entre sí. Al mismo tiempo, los conflictos regionales e

amigo y confidente de Urquiza. Durante la década de 1860 llevó los negocios de éste en la ciudad de Buenos Aires. Fue enviado como agente financiero de la Confederación y en septiembre de 1867 intentó encontrarse con Rosas en Southampton. SÁENZ QUESADA, María, Mujeres de Rosas, Editorial Planeta, Buenos Aires, 1991.

23. ARCHIVO GENERAL DE LA NACIÓN (AGN), Archivo Urquiza, Legajo 301, 01/01/1868 a 22/01/1868. internacionales continuaban agudizándose. ${ }^{24}$ Los 16 días desde la muerte de Paz hasta el arribo de Mitre a Buenos Aires, estuvieron signados por un clima político tensionado por la precariedad de la estructura de gobierno del Poder Ejecutivo y de las aspiraciones y competencias políticas. Como veremos, esta situación tendrá incidencia en los funerales de Paz.

Al mismo tiempo que se debatía sobre quién recaería provisoriamente el Poder Ejecutivo, fueron realizados los funerales del Vicepresidente. El Consejo de Gobierno emitió un decreto disponiendo, en primer lugar, colocar la bandera nacional a media asta en todos los edificios, departamentos públicos y buques de la Armada, invitando al Gobierno de la Provincia y al Arzobispo de Buenos

24. Los dos últimos años de la presidencia de Mitre estuvieron signados por la preocupación de evitar el debilitamiento de su base política porteña y nacional. Además de haber perdido poder en la provincia de Buenos Aires frente al autonomismo, en las provincias de Cuyo y Noroeste se dieron levantamientos armados opositores al proyecto de Estado nacional mitrista, liderados por “Chacho" Peñaloza (1862-1863) y Felipe Varela (1866-1867) atizado este último por el gran descrédito que tuvo en amplios sectores populares las levas para la Guerra del Paraguay. Este conflicto bélico terminaba de darle un contexto todavía más amplio a la crisis política del mitrismo. Luego del entusiasmo inicial -principalmente porteño-, el desgaste de recursos, las desinteligencias entre los mandos de la Triple alianza y el revés de Curupaytí en septiembre de 1866 habían empantanado la guerra en un combate de posiciones, sangriento y prolongado. LETTIERI, Alberto, $\mathrm{La}$ República de las Instituciones. Proyecto, desarrollo y crisis del régimen político liberal en la Argentina en tiempos de la Organización Nacional (1852-1880), Prometeo Libros, Buenos Aires, 2008, pp. 36-37; TERNAVASIO, Marcela (directora) Historia de la Provincia de Buenos Aires: de la organización federal a la federalización de Buenos Aires: 1821-1880, Edhasa, Buenos Aires, 2013, pp. 66-67; SÁBATO, Hilda, Historia de la Argentina. 1852-1890, Siglo XXI editores, Buenos Aires, 2012, p. 131-175. 
Aires a "asociarse a estas demostraciones de dolor". En segundo lugar, se enviaron doce jefes y oficiales del ejército a la casa del Dr. Paz para que hagan guardia de honor con una compañía de infantería del primer regimiento de Guardias Nacionales de la Ciudad. Como tercera medida, se decidió realizar una salva fúnebre de cinco cañonazos, disparando además un tiro cada cuarto de hora, hasta que tenga lugar la inhumación. También se citó a todos los empleados de la nación a la estación del Ferrocarril del Oeste, donde junto con la Guardia Nacional de la Ciudad y la Brigada de Artillería, acompañarían el cuerpo hasta el cementerio de la Recoleta. Por último, todos los empleados de la administración nacional llevaron luto durante ocho días. ${ }^{25} \mathrm{Al}$ mismo tiempo, los regimientos militares brasileros, uruguayos y argentinos acantonados en el frente bélico demostraron idénticas muestras de duelo al tener sus banderas a media asta por 24 horas, portar las armas a la funerala, y realizar una misa en honor del Vicepresidente. ${ }^{26}$

De acuerdo con las crónicas que circularon a través de la prensa, el funeral tuvo tres fases que, coincidiendo con las formas habituales del proceso ritual, sumó toda una simbología en torno al Estado Nacional y la muerte de su principal funcionario del Poder Ejecutivo. El primer momento transcurrió entre la muerte de Paz al mediodía del 2 de enero, hasta la mañana del día 3. Luego de decretar el duelo en las administraciones estatales e invitar

25. El Nacional, Buenos Aires, 02/01/1868.

26. Se llama a la funerala al modo especial de llevar las armas en la infantería. Consiste en poner las bocas de las fusiles mirando al suelo y las culatas hacia arriba apoyando la llave de la sangría del brazo izquierda. Los oficiales llevan la espada debajo del brazo mirando hacia abajo. a las embajadas e iglesias que también lo hicieran, se dispuso que partiera un tren hacia San José de Flores, con guardia de honor del Regimiento de Artillería, junto con banderas y tambores enlutados, así como también los doce jefes y oficiales del ejército nacional antes mencionados. ${ }^{27}$ Por la tarde, se organizó en ese pueblo una compañía de infantería de Guardia Nacional con bandera enlutada, y, a nombre de la provincia de Buenos Aires, se formó otra guardia de honor al cadáver del Dr. Paz, el cual fue velado toda la noche. En estas ceremonias iniciales es interesante destacar la presencia militar que rodeó al cuerpo de Paz, compuesta casi en partes iguales de fuerzas provinciales (las Guardias Nacionales) y nacionales (los jefes del ejército enviados desde Buenos Aires), buscando no sólo vigilar los restos mortales, sino demostrar fuerza y vitalidad ante la situación política.

El segundo momento se inició en la mañana del 3 de enero y finalizó hacia el mediodía de ese mismo día. Se celebró en el Templo de Flores un oficio fúnebre ofrecido por el sacerdote local; luego siguió una misa de cuerpo presente. La distribución espacial de las distintas figuras relacionadas con $\mathrm{Paz}$ traza dos grandes grupos, que se repetirían cuando se lleve adelante su inhumación. E1 primero, estaba compuesto por sus hijos, el cura de la Parroquia de San Ignacio que lo acompañó en sus últimas horas, y también los jefes y oficiales del Ejército Nacional presentes. E1 segundo grupo, ubicado en el lado opuesto de la iglesia, lo componían los vecinos de San José de Flores presididos

27. Las noticias y el decreto hacen referencias a "cajas enlutadas", que consiste en tocar los tambores militares con el parche sin tensión y a la sordina. Esto se reserva aún hoy sólo para los cargos más elevados dentro de la jerarquía militar. 
por el Juez de Paz, el Jefe del Regimiento $1^{\text {o }}$ de Guardia Nacional de campaña, la Municipalidad, algunos empleados del gobierno provincial que se encontraban allí y muchos ciudadanos formando "una numerosísima y selecta concurrencia de damas y caballeros que ocupaban todo el espacio del templo". ${ }^{28}$ De esta manera, por un lado, estaban presentes los familiares directos de Paz junto con los miembros del Estado nacional, y por otro, los vecinos de Flores y las instituciones provinciales y municipales. Mientras esto tenía lugar en aquel pueblo, los cronistas buscaban mostrar a la ciudad de Buenos Aires de duelo: las banderas a media asta en los establecimientos públicos de la Nación y de la Provincia y en las casas de los agentes diplomáticos y consulares, el lúgubre estampido del cañón a intervalos, el tañido de las campanas y los tambores llamando a los ciudadanos a los cuarteles, además del luto general de "los ciudadanos y gran parte de la población extranjera". ${ }^{29}$

El último momento tuvo que ver con la salida, hacia el mediodía, de una comitiva desde la ciudad de Buenos Aires hacia Flores, compuesta por los ministros del Ejecutivo Nacional, el Gobernador de la Provincia y sus ministros, los empleados de todas las administraciones del Estado y ciudadanos. Llegada a San José de Flores, pasó a la casa mortuoria, recibiendo, sobre fusiles y al hombro de oficiales y ciudadanos, el cadáver del Vicepresidente. Luego se dirigió al carruaje que se le tenía preparado, escoltado por dos guardias de honor, ocupando los hijos de $\mathrm{Paz}$ el reservado al gobierno nacional. El

28. La Nación, Buenos Aires, 03/01/1868.

29. El Nacional, Buenos Aires, 03/01/1868. tren partió alrededor de las trece treinta de Flores, ya camino de regreso. ${ }^{30}$

Hacia las dos de la tarde llegó a la estación Central, en la actual plaza Lavalle. Recibido el ataúd fue colocado a pulso en un carruaje fúnebre tirado por cuatro caballos blancos con mantones negros y escudos argentinos, organizándose un convoy que repetiría la distribución espacial de la iglesia, conformado por el siguiente orden: familiares, figuras principales del Estado Nacional, funcionarios provinciales, miembros de la Suprema Corte de Justicia, compañías de Guardias Nacionales, cuerpo diplomático y consular, generales y jefes del Ejército y la Marina, miembros de la Comisión Municipal, demás funcionarios menores y luego toda una flota de coches particulares y ciudadanos de a pie que acompañaron los restos hasta el cementerio. Al partir, la batería 11 de Setiembre hizo una salva fúnebre, y las campanas de los templos tocaron a duelo. Promediando las tres y media de la tarde el convoy fúnebre ingresaba al cementerio de Recoleta, y el cadáver fue conducido nuevamente a pulso hasta la capilla. Sobre la tumba, Guillermo Rawson y Héctor Varela pronunciaron discursos alusivos. $^{31}$

E1 funeral de Marcos Paz tuvo una serie de elementos destacables. El primero de ellos se vincula en cómo los ministros del Poder Ejecutivo Nacional recuperaron su cuerpo desde San José de Flores, y lo retornaron a Buenos Aires. Que fueran éstos quienes lo trajeron de regreso es indicador de la

30. La Nación, Buenos Aires, 03/01/1868.

31. El Nacional, Buenos Aires, 03/01/1868; La Nación, Buenos Aires, 03/01/1868; La Tribuna, Buenos Aires, 03/01/1868 
continuidad que se buscaba establecer entre el difunto y los funcionarios: ellos lo devolvieron al centro del poder. Además, la crisis política que su muerte provocó, obligó a redoblar el esfuerzo de mantener todos los atributos de funeral de Estado: misas, procesión masiva, discursos, etc. ${ }^{32}$ En este sentido, también fue evidente la distancia entre la figura política de Paz y su investidura presidencial. Los discursos pronunciados durante su entierro, $y$ los que circularon por la prensa fueron muy breves y poco elogiosos. En todos estuvo más presente el cargo ejecutivo que tenía por sobre las cualidades y virtudes que solían aparecer en este tipo de homenajes. El discurso de Rawson, el más laudatorio de ellos, fue emblemático:

Fue siempre el Dr. Paz hombre honrado a la par que modesto.

Su vida privada se distingue por su ejemplar consagración y su solicito cariño para su familia y por una lealtad nunca desmentida para sus amigos. ... En la vida pública, en las diversas posiciones a que fue llamado por las exigencias políticas del país, se distinguió siempre por su austera adhesión al cumplimiento del deber. Tuvo la virtud del soldado; subordinado siempre. ${ }^{33}$

32. Estos funerales deben comprenderse en el contexto de la conflictiva vida institucional y política de los países latinoamericanos durante todo el siglo XIX. La consolidación de la autoridad estatal y el establecimiento de símbolos, ritos y palabras que estimularan el sentimiento republicano fue uno de los objetivos principales de esos países, y la Argentina no fue ajena a este proceso. GAYOL, Sandra, "La celebración de los grandes hombres: funerales gloriosos y carreras postmortem en Argentina" en Quinto Sol, Santa Rosa, 2012, V.XVI, No 2, pp. 1-29.

\section{El Nacional, Buenos Aires, 04/01/1868.}

La intervención de Varela, uno de los oradores más reconocidos de la época, resultó llamativamente lacónica, sintetizando el pesar de la noticia y el reconocimiento de la honradez y la justicia del Vicepresidente fallecido. ${ }^{34}$ En cuanto a La Nación, el diario que resumía y defendía las principales ideas del mitrismo, fue mucho más sobrio, demostrando una división interna dentro de este movimiento. Al dar aviso de su muerte, exponía “... Adversarios de aquel magistrado $[\mathrm{Paz}], \ldots \mathrm{y}$ habiendo deseado su separación del mando, podemos sin embargo deplorar con sinceridad el golpe que hiere a un ciudadano en su individualidad y a una familia en su jefe y en su apoyo". ${ }^{35}$ Esta división interna se había acrecentado con el revés en el frente paraguayo, sumado a la cercanía de las elecciones presidenciales. Marcos $\mathrm{Paz}$ tuvo enfrentamientos con el General Gelly y Obes, y también con Rufino de Elizalde, el candidato de Mitre para sucederlo en la presidencia. Estos enfrentamientos se tradujeron en una polémica decisión de Paz de presentar su renuncia al cargo de Vicepresidente en dos oportunidades, a fines de septiembre de 1865 y también hacia junio de 1867 , lo que mostraba posturas irreconciliables hacia adentro del movimiento.

Por otro lado, y a diferencia de las ceremonias habituales, al morir en San José de Flores, Marcos Paz tuvo su funeral divido en dos secciones delimitadas por la distancia geográfica. Esta particularidad potenció la intención de los ministros del Poder Ejecutivo Nacional de mostrarse unidos y fuertes en las ceremonias, ya que el velorio y las misas

34. La Tribuna, Buenos Aires, 04/01/1868; El Nacional, Buenos Aires, 01/01/1868.

35. La Nación, Buenos Aires, 03/01/1868. 
de cuerpo presente ocurrieron en San José de Flores, encabezados por familiares y con mayor presencia militar. Luego, el traslado y entierro en el cementerio de Recoleta, tuvieron mayor asistencia de funcionarios del Ejecutivo y de toda la estructura del Estado Nacional. Al momento de subir al tren que lo llevaría a la ciudad, Paz ya dejaba el ámbito familiar para ser una figura pública: la inhumación en Recoleta sería presidida por figuras políticas y no ya por el entorno familiar.

Las crónicas de los sucesos hacían continua referencia a la participación de "una nutrida concurrencia". Como hemos mencionado previamente, la presencia de la población en los funerales era indispensable, y más aún si se trataba de una figura pública. El recorrido por las calles del cadáver con los ciudadanos como acompañantes era sinónimo de un funeral que se adecuaba a las exigencias de su figura: un profundo sentido de deferencia hacia el gran hombre, el virtuoso y respetable. Sin embargo, como vimos, esta ciudad colmada de acompañantes del féretro de Marcos Paz, no coincide con la imagen semidesierta que tenía días antes, patentada por los mismos redactores. ${ }^{36}$ De esta manera, Paz parece haber conseguido articular todas las formas establecidas de reconocimiento y distinción social, trasladando físicamente el lugar de la ceremonia religiosa y pasando de la esfera civil a la pública en San José de Flores. También conseguiría tener sus celebraciones

36. Los funerales de Estado no podían prescindir de la multitud. Si en la casa de gobierno eran las elites gobernantes quienes sostenían la ceremonia enfatizando su importancia colectiva ante la muerte de uno de sus miembros más prominentes, en las calles el liderazgo lo ejercía la multitud. GAYOL, Sandra, "La celebración...", Op. Cit., p. 12. posteriores. Apenas finalizado el peor período de la epidemia, se organizaron misas en su honor el 6 de febrero, en la Iglesia Catedral.

Finalmente, el fallecimiento de Paz dejó abierto el debate sobre la necesidad de proveer y estipular claramente mecanismos institucionales para la sucesión del poder. Si bien desde 1866 se debatía en el Congreso Nacional la reforma del artículo 75 de la Constitución Nacional, el proyecto presentado y aprobado en el Senado no lo fue en la Cámara de Diputados, ${ }^{37}$ y para fines de 1867 el debate estaba estancado. Luego de la muerte de Paz, el Senado nuevamente dio forma a un proyecto de ley de acefalia en el mes de mayo, y el 19 de septiembre -a menos de un mes de la asunción de Sarmiento como nuevo presidente- se debatió y sancionó en el congreso la Ley No 252. Esta establecía que en caso de ausencia del Presidente y Vicepresidente de la Nación, el Poder Ejecutivo sería desempeñado en primer lugar por el Presidente Provisorio del Senado, en segundo lugar por el Presidente de la Cámara de Diputados, y a falta de éstos, por el Presidente de la Corte Suprema. Además, el funcionario llamado a ejercer el Poder Ejecutivo debía convocar a elecciones dentro de los treinta días siguientes a la fecha de su instalación en el cargo. ${ }^{38}$

37. El primer proyecto fue presentado en la Cámara de Senadores por Joaquín Granel, y proponía que en caso de imposibilidad del presidente y vice, fuera el presidente del Senado quien ejerza el Poder Ejecutivo. Un año después, en julio de 1867, fue aprobado por la Cámara, y pasado a Diputados, que en sesión del 9 de septiembre de 1867 rechazó el proyecto. BARRANCOS Y VEDIA, Fernando, Alternativas..., Op. Cit., p. 4

38. Esta ley se utilizó en dos oportunidades. La primera fue el 29 de marzo de 1962, cuando Arturo Frondizi fue depuesto por un golpe militar y su Vicepresidente había renunciado previamente. Los golpistas decidieron 


\section{Consideraciones finales}

En el artículo hemos intentado demostrar que la llegada del cólera produjo una serie de cambios cualitativos en la sociedad de Buenos Aires. Habituados a otro tipo de enfermedades, los porteños quedaron atenazados por la incertidumbre y el pánico, además de experimentar una crisis social solo comparable con conflictos bélicos o desastres naturales. Ante este episodio traumático, los deudos y allegados de los difuntos se enfrentaban con la dislocación y transformación de los rituales fúnebres, lo que acentuaba el dramatismo de la situación. Para intentar superar este período crítico que afectaba el proceso ritual marcado por la costumbre y la religión, familiares y allegados buscaron sustitutos, intentando con ello mantener un umbral de normalidad.

También nos propusimos probar que estos rituales fúnebres podían ser utilizados para superar conflictos que excedían el alto número de decesos. Las epidemias no sólo producían pánico y terror, sino que transformaban la coyuntura política, acelerando las disputas entre facciones y la lucha por espacios de poder. Además, la crisis de mortalidad ocasionó problemas dentro

darle un marco de legalidad a su accionar y la presidencia la asumió el Presidente Provisorio del Senado, José María Guido. La segunda tuvo lugar en 1973, cuando renunciaron el Presidente Héctor Cámpora y el Vicepresidente Vicente Solano Lima, asumiendo provisoriamente el Poder Ejecutivo el Presidente de la Cámara de Diputados, Raúl Lastiri. La ley 252 se mantendrá vigente hasta 1975 , cuando se la sustituya por la ley No20.972. En ella se anulaba el llamado a elecciones, y establecía que el Congreso Nacional elegiría por votación y mayoría absoluta a los nuevos funcionarios. Esta fue la ley que se utilizó durante los episodios de diciembre de 2001 y principios de 2002 para elegir el nuevo presidente. de las instituciones del Estado Nacional, al no quedar claros los procedimientos para gobernar en caso de ausencia de los principales funcionarios del Poder Ejecutivo. Hemos analizado el fallecimiento y los funerales del vicepresidente Marcos $\mathrm{Paz}$ en enero de 1868, una figura clave para mantener el orden institucional dada la situación política. Argumentamos que ante el escenario de precariedad institucional que quedó con su muerte, las exequias sirvieron para mostrar unidad, orden y fortaleza del Poder Ejecutivo Nacional. En este sentido, los funerales de $\mathrm{Paz}$ recubrieron al Vicepresidente de un reconocimiento público que no había gozado hasta entonces.

\author{
Recibido: 13-10-2016 \\ Aceptado: 17-03 -2017 \\ Publicado: 05-12-2017
}

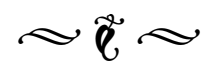




\section{Bibliografía}

AAVV, Patrimonio cultural en cementerios y rituales de la muerte, Gobierno de la Ciudad de Buenos Aires, Buenos Aires, 2005, (dos volúmenes).

ÁLVAREZ, Adriana, "La aparición del cólera en Buenos Aires (Argentina), 1865-1996”, en HiSTOReLo. Revista de Historia Regional y Local, Medellín, 2012, V. IV, No 8, pp. 174-207.

ÁLVAREZ, Adriana, "El rol de los Lazaretos en el control del cólera y la fiebre amarilla. Buenos Aires 1870-1915”, en Historia Revista, Goiás, 2004, V. IX, No 2, pp. 287-317.

ÁLVAREZ, Adriana, MOLINARI, Irene y Reynoso, Daniel (editores) Historias de enfermedades, salud y medicina en la Argentina de los siglos XIX-XX, Universidad Nacional de Mar del Plata, Mar del Plata, 2004.

ARIES, Philippe, El hombre ante la muerte, Taurus, Madrid, 1983.

BARRAL, María Elena, De sotanas por la pampa. Religión y sociedad en el Buenos Aires rural tardocolonial, Prometeo libros, Buenos Aires, 2007.

BARRANCOS y VEDIA, Fernando, Alternativas de la acefalia presidencial, Academia Nacional de Ciencias Morales y Políticas, Buenos Aries, 2004.

CARBONETTI, Adrián, "Medicalización y cólera en Córdoba a fines del siglo XIX. Las epidemias de 1867-68 y 1886-87”, en Anuario de Historia Regional y de las Fronteras, Bucaramanga, 2016, V. XXI, No 2, pp. 285-309.

CARBONETTI, Adrián, RODRIGUEZ, María Laura, RIMONDA, Noelia, Martina, Camila, "Las epidemias de cólera en Córdoba a través del periodismo: la oferta de productos preservativos y curativos durante la epidemia de 1867-1868”, en Historia, Ciencia, Saúde Manguinhos, Rio de Janeiro, 2007, V. XIV, No 2, pp. 405-419.

DIODATI, Lilian y LIÑAN, Nora, "Gestualidad y sentido de la muerte en Buenos Aires durante la primera mitad del siglo XIX”, en GODOY, Cristina y HOURCADE, Eduardo (compiladores) La muerte en la cultura. Ensayos históricos, Universidad Nacional de Rosario Editora, Rosario, 1993, pp. 41-53.

EVANS. Richard, Death in Hamburg: Society and Politics in the Cholera Years, Penguin Books, New York, 1987.

FIQUEPRON, Maximiliano, Morir en las grandes pestes: Estado, sociedad y representaciones sobre la muerte durante las epidemias de cólera y fiebre amarilla en Buenos Aires. (1856-1886), Tesis doctoral, Universidad de General Sarmiento, 2015.

FIQUEPRON, Maximiliano, “Cadáveres, epidemias y funerales en Buenos Aires (1856-1886)”, en GAYOL, Sandra y KESSLER, Gabriel (editores) Muerte, politica y sociedad en la Argentina, Edhasa, Buenos Aires, 2015, pp. 227 - 250. 
GAYOL, Sandra, "Los despojos sagrados: funerales de estado, muerte y política en la Argentina del Centenario", en TATO, María Inés y CASTRO, Martín (compiladores) Del Centenario al peronismo. Dimensiones de la vida politica argentina, Imago Mundi, Buenos Aires, 2010, pp. 9-32.

GAYOL, Sandra, "La celebración de los grandes hombres: funerales gloriosos y carreras post-mortem en Argentina" en Quinto Sol, Santa Rosa, 2012, V. XVI, No 2, pp. 1-29. GAYOL, Sandra y KESSLER, Gabriel (compiladoras) Muerte, politica y sociedad en la Argentina, Edhasa, Buenos Aires, 2015.

LETTIERI, Alberto, La República de las Instituciones. Proyecto, desarrollo y crisis del régimen político liberal en la Argentina en tiempos de la Organización Nacional (1852-1880, Prometeo Libros, Buenos Aires, 2008.

MUNICIPALIDAD DE LA CIUDAD DE BUENOS AIRES, Actas del Concejo Municipal de la ciudad de Buenos Aires, correspondiente al año 1867, Talleres Gráficos “Optimus”, Buenos Aires, 1911.

MUNICIPALIDAD DE LA CIUDAD DE BUENOS AIRES, Actas del Concejo Municipal de la ciudad de Buenos Aires, correspondiente al año 1871, Talleres Gráficos “Optimus”, Buenos Aires. 1911.

MUNICIPALIDAD DE LA CIUDAD DE BUENOS AIRES, Actas del Concejo Municipal de la ciudad de Buenos Aires, correspondiente al año 1870, Talleres Gráficos “Optimus”, Buenos Aires, 1911.

PAYNE, Richard, "Locating Buddhism, Locating Psychology”, en Young-Eisendrath, P y MURAMOTO, Shoji (editores) Awakening and Insight: Zen Buddhism and Psychotherapy, Brunner/Routledge, Londres y New York, 2002, pp. pp. 172-186.

PENNA, José, El cólera en la Argentina, Editorial Jacobo Peuser, Buenos aires, 1897.

PARKIN, David, "Ritual", en BALTES, Paul and SMELSER, N, International Encyclopedia of the Social E Behavioral Sciences, Elsevier, Amsterdam, 2001, pp. 13368-13371. Disponible en: <http://www. sciencedirect.com/science/referenceworks/9780080430768>.

PRIETO, Agustina [et. al], Ciudad de Rosario, Editorial Municipal de Rosario, Rosario, 2010.

RANGER, Terrence y SLACK, Paul (editores) Epidemics and Ideas: essays on the historical Perception of Pestilence, Cambridge University Press, Cambridge, 1992.

REIS, Joao, A morte e uma festa. Ritos funebres e revolta popular no Brasil do século XIX, Companhia das letras, Sao Paulo, 1991.

REIS, Joao, "O cotidiano da morte no Brasil Oitocentista" en NOVAIS, Fernando (director) Historia da vida privada no Brasil. T. II, Imperio: a corte e a modernidade nacional, Compania das Letras, Sao Paulo, 1997.

ROSENBERG, Charles, The Cholera Years: The United States in 1832, 1849 and 1866, The University of Chicago Press, Chicago, 1962.

SÁBATO, Hilda, Historia de la Argentina. 1852-1890, Siglo XXI editores, Buenos Aires, 2012, pp. 131-175.

SÁENZ QUESADA, María, Mujeres de Rosas, Editorial Planeta, Buenos Aires, 1991. 
SCENNA, Miguel Ángel, Cuando murió Buenos Aires. 1871, Cántaro, Buenos Aires, 1974.

SNOWDEN, Frank, Naples in the Time of Cholera, 1884-191, Cambridge University Press, Cambridge, 1995.

SUZUKI, Hiraku, The price of Death: The Funeral Industry in Contemporary Japan, Stanford University Press, Stanford, 2000.

TERNAVASIO, Marcela (directora) Historia de la Provincia de Buenos Aires: de la organización federal a la federalización de Buenos Aires: 1821-1880, Edhasa, Buenos Aires, 2013.

VISACOVSKY, Sergio (compilador) Estados Críticos: la experiencia social de la calamidad, Al Margen, La Plata, 2011. 